\title{
Research Article \\ Self-Excited Single-Stage Power Factor Correction Driving Circuit for LED Lighting
}

\author{
Yong-Nong Chang \\ Department of Electrical Engineering, National Formosa University, Yunlin County 63201, Taiwan \\ Correspondence should be addressed to Yong-Nong Chang; ynchang@nfu.edu.tw
}

Received 19 February 2014; Accepted 3 March 2014; Published 27 March 2014

Academic Editor: Teen-Hang Meen

Copyright (C) 2014 Yong-Nong Chang. This is an open access article distributed under the Creative Commons Attribution License, which permits unrestricted use, distribution, and reproduction in any medium, provided the original work is properly cited.

\begin{abstract}
This pa per proposes a self-excited single-stage high power factor LED lighting driving circuit. Being featured with power factor correction capability without needing any control devices, the proposed circuit structure is with low cost and suitable for commercial production. The power factor correction function is accomplished by using inductor in combination with a half-bridge quasi resonant converter to achieve active switching and yield out voltage regulation according to load requirement. Furthermore, the zero-voltage switching in the half-bridge converter can be attained to promote the overall performance efficiency of the proposed circuit. Finally, the validity and production availability of the proposed circuit will be verified as well.
\end{abstract}

\section{Introduction}

Due to the recent breakthrough in fabricating process [1-3] and progressive improvement of lighting efficiency, LED is featured with ecofriendly, free-Mercury, and low power consumption, compactness, high efficiency, and so on, thus prevailing over other lighting devices in the lighting applications. The LED (light emitting diode) lighting products are inclined toward diversified growth and application penetration. The global market scale of LED lighting products is predicted to come up to several tens of billions USA dollars in the coming year 2015. The demand of LED lighting equipment will be ever increasing.

Vast switching circuits are inevitably used in energy industry. The PFC (power factor correction) circuit is, therefore, studied and developed in the past two decades [4-6] to meet the IEC (International Electrotechnical Commission) requirements in the harmonic current standard [7]. In consequence, it is indispensable feature for the power converter to possess the power factor correction function. Power factor correction circuits can be categorized into passive type [8-12] and active type [13-15]. Passive type PFC circuit is basically composed of inductor and capacitor. It possesses the feature of low cost without needing extra control circuit. However, though active type PFC circuit possesses better power factor, it is costly due to needing extra control circuit. In commercial applications, the cost consideration has led the extensive usage to meet PFC standard.

The power switch driving method comprises two types: self-excitation and external excitation ones. In a selfexcitation circuit, resonant current feedback signal is sampled to generate driving signal without needing extra control circuit. However, the circuit performance and output characteristics are drastically affected by the device parameters, such as storage time and saturation point of transformer. The operation frequency of resonant circuit plays the key role in performance stability. The design and device selection involve more disciplines and strict conditions. Hence, the circuit parameters must be carefully envisaged. It is relatively difficult in design. Although external excitation control circuit is complex, it is both flexible and rich in design. The operating frequency of inverter and duty cycle of switch can be adjusted at will. It could, therefore, easily carry out dimming function and fault protection design. With the addition of the preceding functions, the circuit complexity inevitably increases and control IC is indispensable. Consequently, the fabricating cost will increase.

The commonly used two-stage high power factor circuit not only possesses enormous device parts and does not meet cost reduction, but also encompasses one stage to 
correct power factor and another converter stage to perform voltage and current regulation. The switches therein are all hard switching basically. Therefore, the switching losses are drastically large, thus invoking heat dissipation problem. The accompanied losses in both PFC stage and conversion stage will result in poor overall efficiency $[16,17]$. However, single-stage high power factor circuit structure integrates both stages into one by employing the same power switches to handle both PFC and conversion processes to reduce the power loss. Despite the fact that the switching modes turn to be complicated in nature and the determination of device parameters becomes strict $[18,19]$, the single-stage high power factor circuit both reduces the number of devices and avoids conversion loss between stages, thus enhancing the overall efficiency.

The self-excitation circuit structure proposed in this research utilizes resonant tank to resonate and drive the power switches. With the absence of integrated circuit and control IC, the cost can be greatly reduced. However, the traditional self-excitation circuit is inherited with poor power factor. A power correction circuit is required to promote the power factor, while it may produce low frequency noise and is bulky in size.

This research intended to design a self-excitation singlestage high power factor driving circuit for LED lighting to overcome the proceeding drawbacks. Self-excitation technique is introduced to drive control signal and, therefore, achieves the active power factor correction function. In addition, dramatic cost and circuit complexity reductions are fulfilled by the absence of integrated circuits. The usage of half-bridge resonant technique can effectively increase the operating frequency to avoid audible noise production along with output voltage and current regulations. Furthermore, the zero-voltage-switching function furnished by resonant circuit can effectively reduce the high-frequency switching loss and tackle the heat dissipation problem. Consequently, the proposed self-excitation high power factor single-stage driving circuit is featured with advantages such as simple structure, size reduction, and low complexity.

\section{Configuration}

Figure 1 is the circuit configuration of a self-excitation singlestage high power factor driving circuit for LED lighting proposed in this research. It is majorly constituted by a PFC inductor $L_{\mathrm{PFC}}$, resonant inductor $L_{r}$, and resonant capacitor $C_{r}$. Besides, the self-excitation circuit comprises energy storage capacitor $C_{\text {bus }}$, resistor $R_{1}$, capacitor $C_{1}$, and silicon diode for alternating current (SIDAC). The selfexcitation mechanism is accomplished by switching halfbridge converter to store and release energy on PFC inductor $L_{\text {PFC }}$ to complete high power factor performance. For lack of control IC, the cost can be curtailed consequently. By utilizing self-excitation along with half-bridge resonant switching technique, the output voltage and current can meet the LED lighting load requirement. The technique of resonant converter will equip the power switch with zero-voltageswitching function and enhance the overall efficiency.
Self-excitation electronic ballast has the advantage of generating driving signal by itself without needing extra control circuit, thus saving the budget. In this research, a simple circuit using resistor $R_{1}$ and capacitor $C_{1}$ is applied to accomplish the self-excitation purpose. Figure 2 shows the current flow path of the first trigger operation.

As illustrated in the above figure, the half-bridge resonant switch is left open due to lack of triggering signal. Therefore, the current will pass through the intrinsic diode $D_{1}$ inherited on switch to pump the energy to storage capacitor $C_{\text {bus }}$. Next, the energy on $C_{\text {bus }}$ will charge energy storage capacitor $C_{1}$ via resistor $R_{1}$ until the voltage across $C_{1}$ gets enough voltage to turn on SIDAC. After breakdown, the SIDAC starts to transfer energy to signal transformer $T_{\text {signal2 }}$ and half-bridge switches begin to switch complimentarily. Through the above operation mode, the triggering signal of half-bridge resonant switching gets ready.

Figure 3 is the triangular inductor current $i_{L_{\mathrm{PFC}}}$ of power factor corrector. The peak value of current is proportional to the absolute value of switching-on instant of input sinusoidal voltage; that is, the dashed line waveform of current peak $i_{p \text {,peak }}(t)$ is proportional to the absolute value $\left|V_{\text {in }}\right|$. This leads to source current $i_{\text {in }}(t)$ being proportional to source voltage $V_{\text {in }}(t)$ and in-phase each other, thus bettering the power factor.

In Figure 4, LED lighting set comprises a LED set and a high frequency transformer. In other words, the LEDs are powered by an isolated power source and the LED lighting set is equivalent to a resistor $R_{\mathrm{LED}}$. A pair of power switches are triggered complimentarily. The input high dc voltage will turn into a high frequency sinusoidal signal after resonant switching of the combination of half-bridge inverters, $L_{r}$ and $C_{r}$. Also, the operating characteristics are controlled in the inductive region. The advantages of the preceding conversion include (1) DC high voltage being converted to high frequency sinusoidal wave (it both meets load requirement and reduces EMI due to its nearly sinusoidal form); (2) the increased frequency encompasses extra merits of increased lighting efficiency, reduced magnetic device low frequency noise, declined lamp flickering, compacted and magnetic device; (3) operating characteristics being controlled in the inductive region (the resonant current will lag behind square wave voltage). Before the conduction of resonant switch, current passes through body diode of switch, thus yielding zero-voltage stress on switch during switching action.

\section{Circuit Operation}

In this research, all power switches comprise MOSFET. Figure 5 illustrates the waveforms of triggering signal and voltage across and current through the passive devices. Trigger signals $V_{\mathrm{GS} 1}$ and $V_{\mathrm{GS} 2}$ are applied to control halfbridge resonant switches. The current $i_{L_{\mathrm{PFC}}}$ passing through power factor correction inductor can be controlled as well to arrive at power factor correction. After cautious selection of resonant inductor $L_{r}$ and capacitor $C_{r}$, resonant current waveform $i_{r}$ is shown in Figure 5. The voltage across on switches is controlled to zero before being turned on. Figure 5 


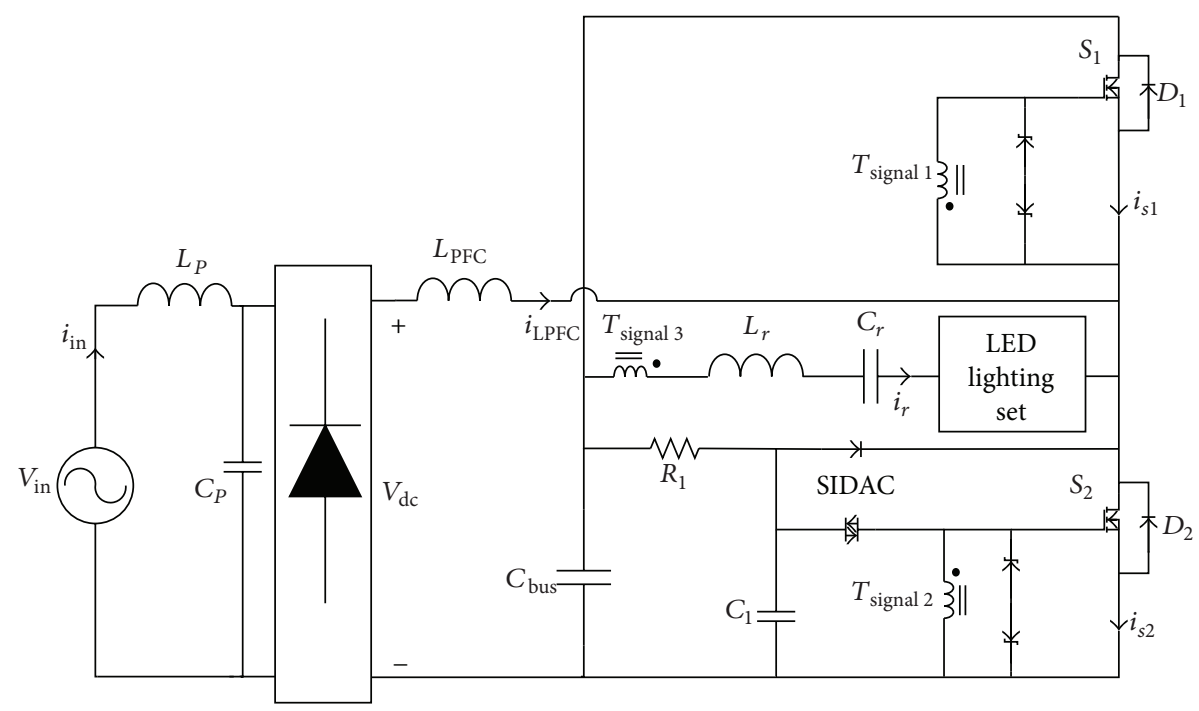

FIGURE 1: Self-excitation single-stage high PF circuit configuration.

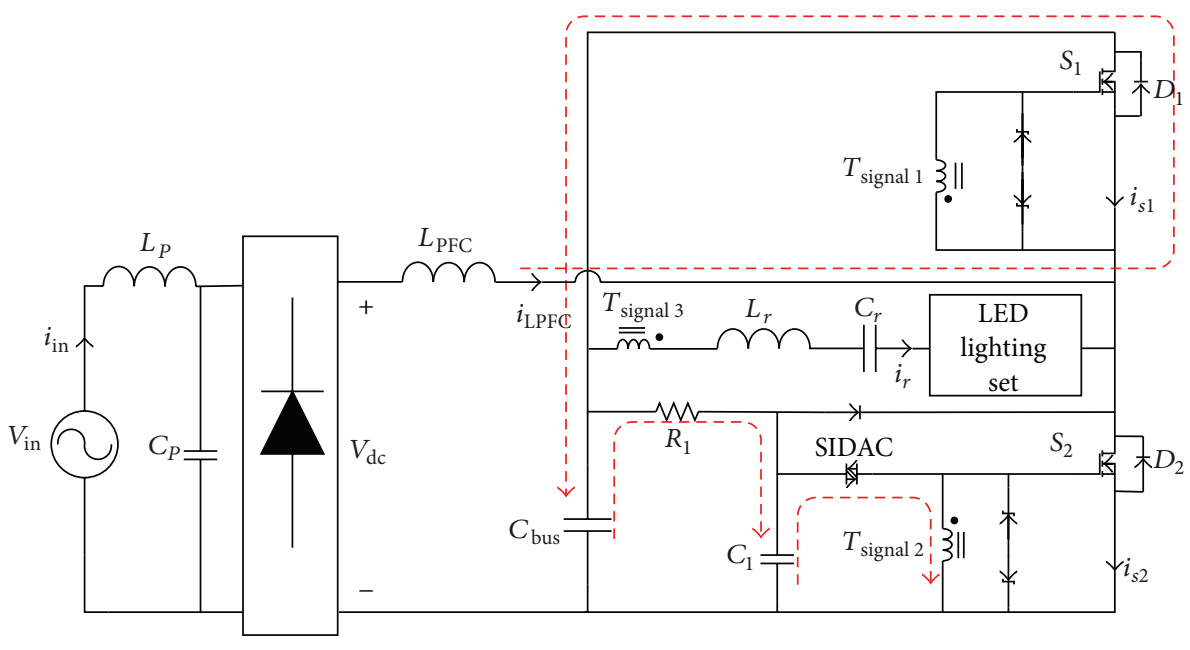

FIGURE 2: Current path of first trigger in self-excitation circuit.

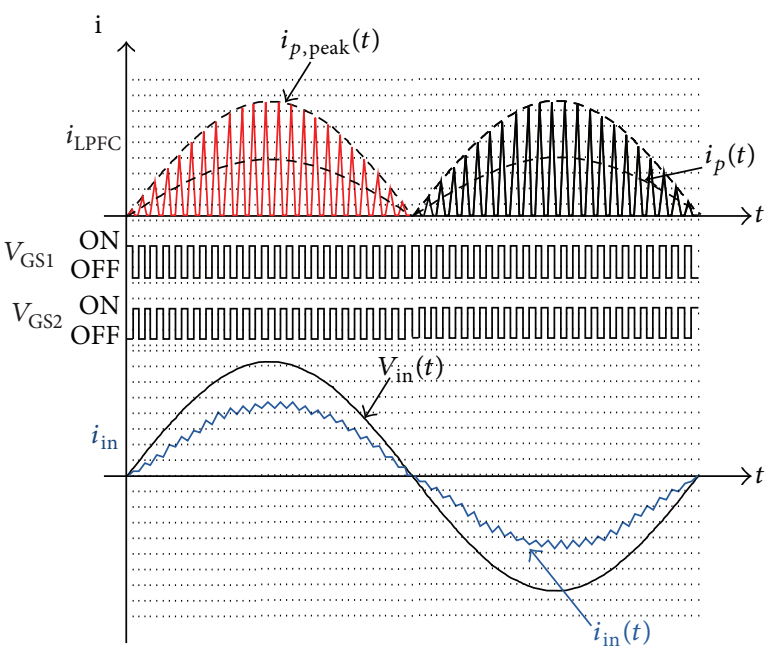

FIGURE 3: PFC inductor current waveform and input current waveform.

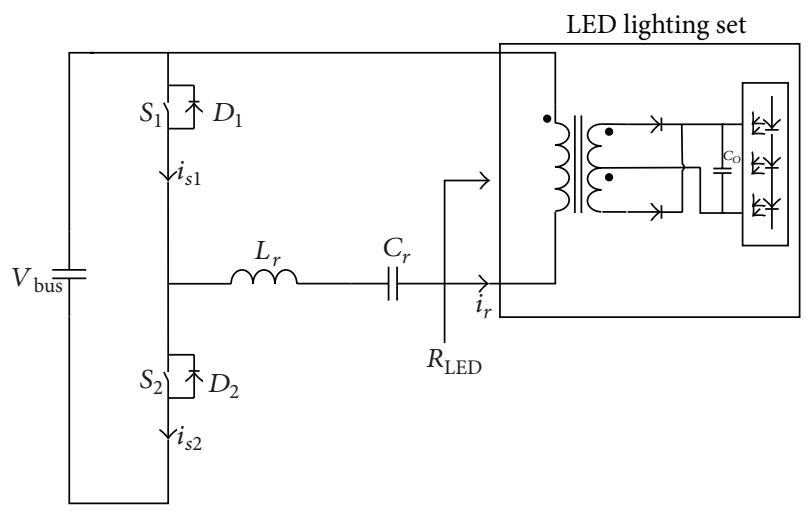

FIGURE 4: Half-bridge resonant converter.

demonstrates the current waveforms $i_{s 1}$ and $i_{s 2}$. Zero-voltage switching is apparently observed. 


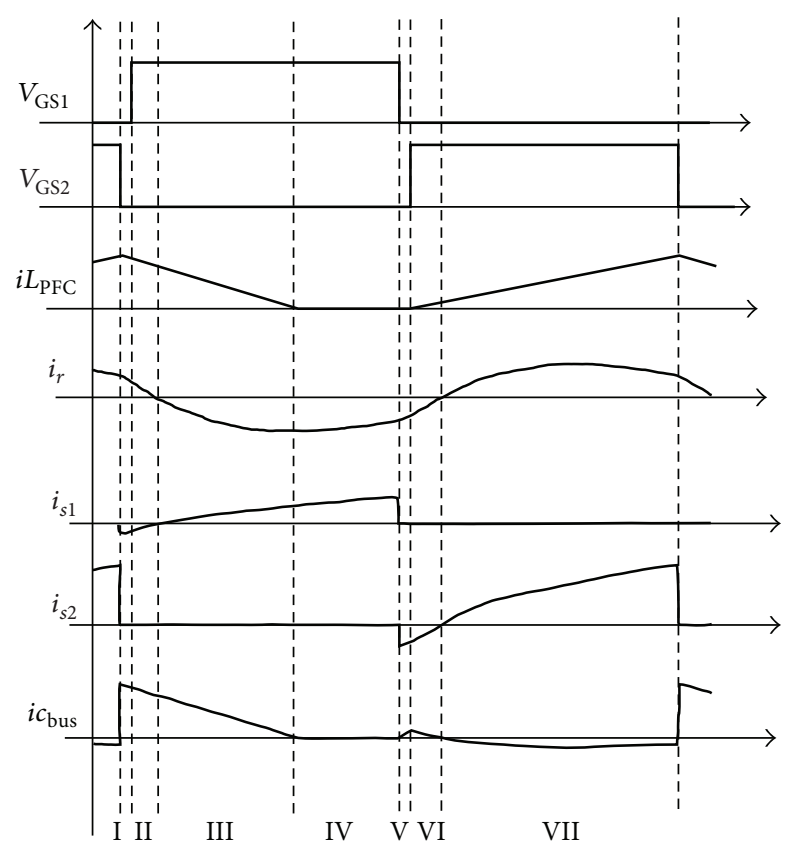

FIgURE 5: Triggering signals and current waveforms.

To simplify the parameter design and analyze the operation models, the following assumptions must be proclaimed in advance.

(1) All diodes and switching devices are ideal.

(2) Switching frequency is far greater than grid frequency.

(3) The voltage $V_{\text {bus }}$ on energy storage capacitor is looked upon as ideal voltage source. Resonant tank current $i_{r}$ is viewed as ideal current source without ripple components.

(4) Resonant quality factor is large enough to assume resonant to be sinusoidal.

Operation Mode I. By inspecting the triggering sequence and current waveforms in Figure 5, the triggering signals $V_{\mathrm{GS} 1}$ and $V_{\mathrm{GS} 2}$ are both under low state. Hence, the resonant current $i_{r}$ does freewheeling through intrinsic diode $D_{1}$ of switch $S_{1}$ as demonstrated in Figure 6(a). Meanwhile, inductor $L_{\mathrm{PFC}}$ releases energy via intrinsic diode and energy storage capacitor $C_{\text {bus }}$.

Operation Mode II. The triggering signal $V_{\mathrm{GS} 1}$ is in the high state. As shown in Figure 6(b), resonant current $i_{r}$ passes through intrinsic diode $D_{1}$ of switch $S_{1}$ with freewheeling mechanism. Inductor $L_{\mathrm{PFC}}$ keeps on releasing energy via intrinsic diode and energy storage capacitor $C_{\text {bus }}$.

Operation Mode III. As shown in Figure 6(c), the resonant current $i_{r}$ commutates; switch $S_{1}$ turns on. Inductor $L_{\mathrm{PFC}}$ releases energy through resonant tank and capacitor $C_{\text {bus }}$.

Operation Mode IV. After energy storage inductor $L_{\mathrm{PFC}}$ releases energy completely, this mode starts as illustrated in Figure 6(d). Merely resonant current $i_{r}$ keeps on flowing through $S_{1}$ till the next mode.

Operation Mode V. According to sequence waveforms shown in Figure 5, a dead time design is considered in the circuit for avoiding simultaneous conduction of power switches and possible damage. As displayed in Figure 6(e), both the triggering signals are at low state. Thus, resonant current $i_{r}$ performs freewheeling through $C_{\text {bus }}$ and intrinsic diode $D_{2}$ of power switch $S_{2}$.

Operation Mode VI. The triggering signal $V_{\mathrm{GS} 2}$ is at the high state in this stage as shown in Figure 6(f). Inductor $L_{\mathrm{PFC}}$ begins to store energy via resonant tank and energy storage capacitor $C_{\text {bus }}$. Resonant current $i_{r}$ continues to do freewheeling through intrinsic diode $D_{2}$.

Operation Mode VII. In Figure 6(g), the resonant current $i_{r}$ commutates and power switch $S_{2}$ turns on. Inductor $L_{\mathrm{PFC}}$ is storing energy via $S_{2}$.

By utilizing the simple trigger signals to accomplish the operation of half-bridge resonant converter, the presented driving circuit also possesses the following advantages: (1) reducing EMI; (2) lowering low frequency noise; (3) providing zero-voltage switching.

\section{Circuit Analysis}

Prior to the design of parameters, the specifications of circuit and load must be specified in advance. It includes input voltage $V_{\text {in }}$, switching frequency $f_{s}$, half-bridge resonant frequency $f_{r}$, input real power $P_{\text {in }}$, output real power $P_{\text {out }}$, lamp current $i_{r}$, lamp resistance $R$, duty cycle $D$, and allowable voltage ripple on energy storage capacitor. Afterwards, the design of circuit device parameter can be embarked on.

The proposed AC/DC converter is connected to and supplied by power grid. Thus, the source voltage can be written as

$$
V_{\text {in }}(t)=V_{m} \sin (\omega t) .
$$

Because the switching frequency of half-bridge converter far exceeds the grid frequency as shown in Figure 3, the high frequency switching action will be accomplished within the grid frequency envelope. Thus, $i_{p \text {,peak }}(t)$ can be expressed by (2). By solving out the triangle area of (2), the obtained result is described by $i_{p}(t)$ as written in (3). Next, $i_{p \text {,peak }}(t)$ is integrated over half period and the average value can be achieved, as shown in (4), where $T_{s}$ is the switching period:

$$
\begin{gathered}
i_{p \text {,peak }}(t)=\frac{V_{m} \sin (\omega t) T_{s}}{2 L_{\mathrm{PFC}}}, \\
i_{p}(t) \cong \frac{1}{2} \times T_{s} \times i_{p, \text { peak }}(t), \\
i_{\text {in }}(t) \cong \frac{1}{T_{s}} \int_{0}^{T_{s}} i_{p}(t) \cdot d(t)=\frac{V_{m} T_{s}}{4 L_{\mathrm{PFC}}} \sin (\omega t) .
\end{gathered}
$$

Based on input voltage $V_{\text {in }}(t)$ of (1) and input current $i_{\text {in }}(t)$ of (4), the average input power $P_{\text {in }}$ can be determined according to (5). With circuit efficiency being taken into 


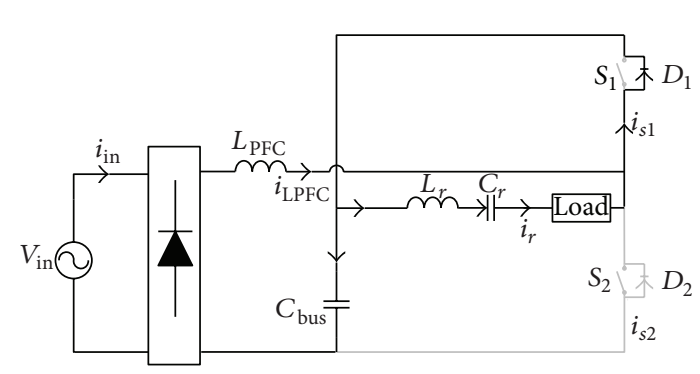

(a) Mode I

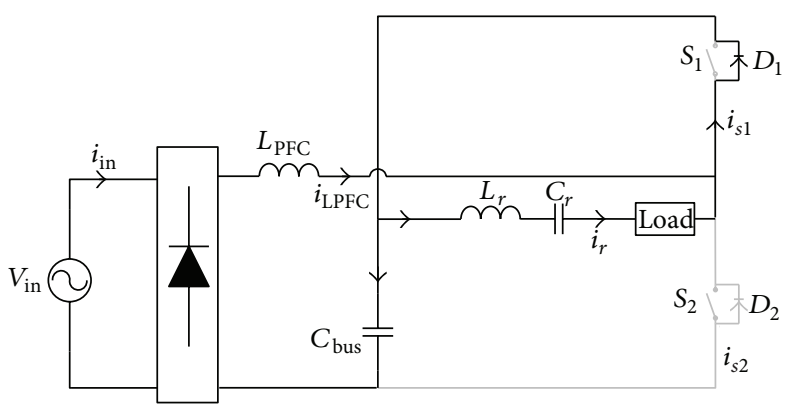

(b) Mode II

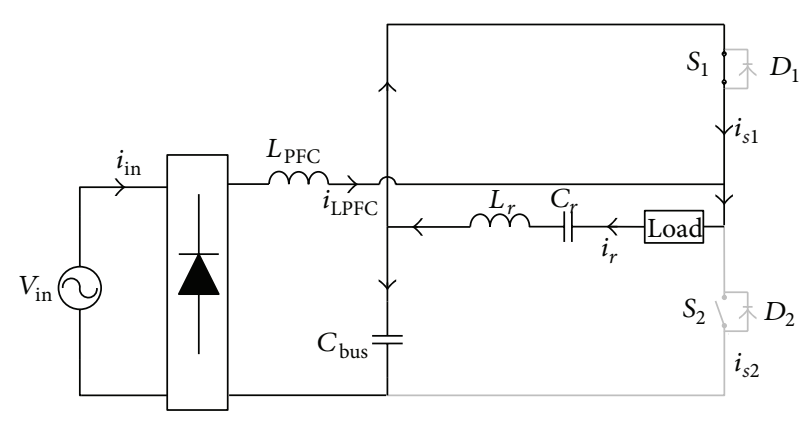

(c) Mode III

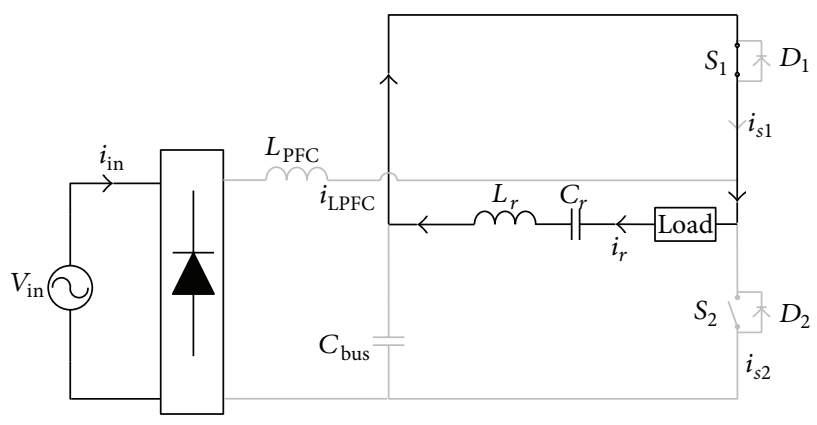

(d) Mode IV

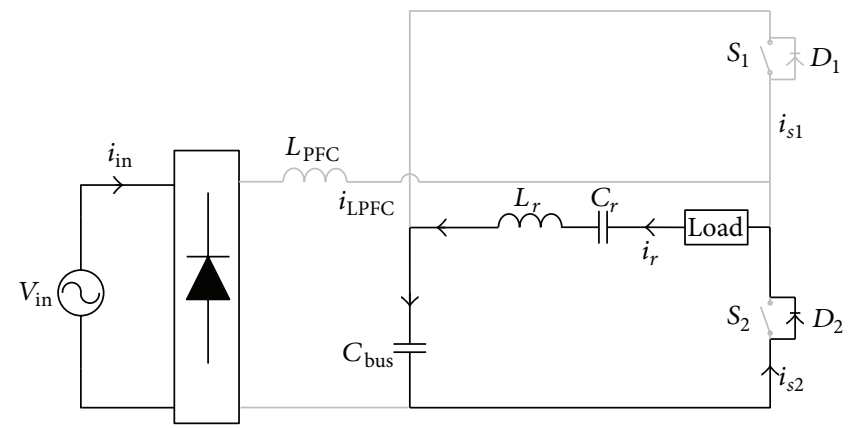

(e) Mode V

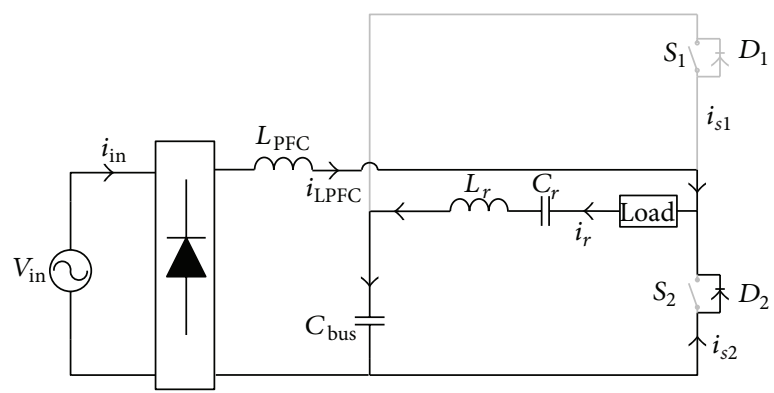

(f) Mode VI

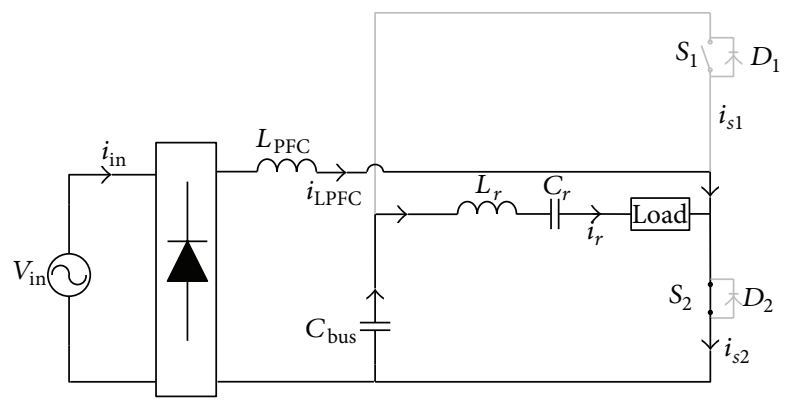

(g) Mode VII

FIGURE 6: Current path of operation mode.

account, the output power $P_{\text {out }}$ of converter can be expressed as in (6). By further mathematical calculation, the quantity of PFC inductor $L_{\mathrm{PFC}}$ can be written as in (7):

$$
P_{\text {in }} \cong \frac{1}{2 \pi} \int_{0}^{2 \pi} v_{\text {in }}(t) \cdot i_{\text {in }}(t) d(\omega t)=\frac{V_{m}^{2}}{8 L_{\mathrm{PFC}} f_{s}},
$$

$$
\begin{gathered}
P_{\text {out }}=\eta \cdot P_{\text {in }}=\frac{\eta \cdot P_{\text {in }}}{8 L_{\mathrm{PFC}} f_{s}}, \\
L_{\mathrm{PFC}}=\frac{\eta \cdot V_{m}^{2}}{8 L_{\mathrm{PFC}} f_{s}} .
\end{gathered}
$$

Figure 7 shows the relationship of capacitor voltage with respect to capacitor input power. It is clearly seen that 


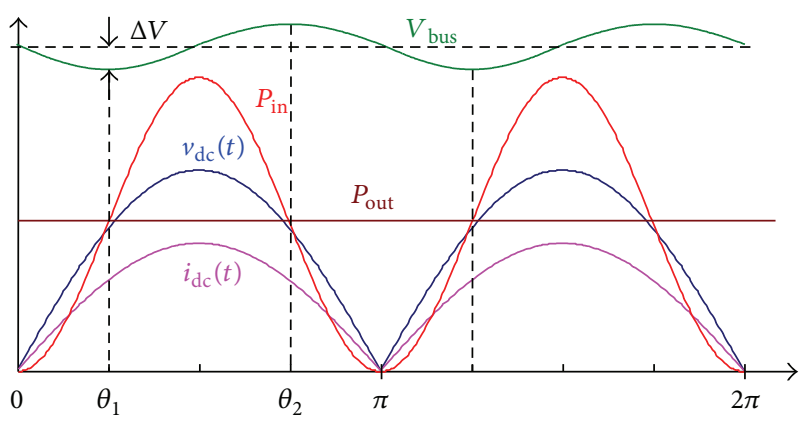

FIGURE 7: Capacitor voltage and electric energy relationship.

capacitor voltage $V_{\text {bus }}$ lags capacitor input power with angle $\theta$. By integrating (8), capacitor input energy is derived as expressed by (9):

$$
\begin{gathered}
P_{C_{\text {in }}}(t)=V_{\text {in }}(t) \times i_{\text {in }}(t), \\
P_{\text {out }}=\frac{1}{2 \pi} \int_{0}^{2 \pi} P_{\text {in }}(t) d t=\frac{1}{2} V_{m} I_{m} .
\end{gathered}
$$

According to energy conservation law, the energy stored on capacitor is identical to its output as expressed by (10). The solutions of $\theta$ can obtain from (10). They are $\theta=\pi / 4$ and $3 \pi / 4$. Substitute $\theta_{1}=\pi / 4$ and $\theta_{2}=3 \pi / 4$ into integration form of (11) as lower and upper limit. The relationship among $\Delta W, \omega$, and $P$ can satisfy (10). Equation (13) is another form of $\Delta W ;(11)$ and (12) are equal. Also, (11) can be expressed by (13), wherein $2 \Delta V / V_{\text {bus }}$ is the ripple factor. The reactance of energy storage capacitor is achieved and written as in (13):

$$
\begin{gathered}
V_{m} I_{m} \sin ^{2}(\theta)=\frac{1}{2} V_{m} I_{m}, \\
\Delta W=\int_{\theta_{1}}^{\theta_{2}} V_{m} I_{m} \sin ^{2}(\omega t)-\frac{1}{2} V_{m} I_{m} d \omega t \\
=\int_{\pi / 4}^{3 \pi / 4} V_{m} I_{m} \sin ^{2}(\omega t)-\frac{1}{2} V_{m} I_{m} d \omega t=\frac{P}{\omega}, \\
\Delta W=\frac{1}{2} C\left[\left(V_{\text {bus }}+\Delta V\right)^{2}-\left(V_{\text {bus }}-\Delta V\right)^{2}\right], \\
\Delta W=C \times V_{\text {bus }}^{2} \times \frac{2 \Delta V}{V_{\text {bus }}}, \\
C=\frac{P}{\omega \times V_{\text {bus }}^{2} \times \text { ripple }} .
\end{gathered}
$$

Figure 8 illustrates that the equivalent resonant circuit composed of resonant inductor $L_{r}$ and resonant capacitor $C_{r}$. The associated parameters can be decided by using Ohm's law.

Firstly, the stored energy in the form of DC voltage on capacitor is converted to voltage $V_{\mathrm{AB}}$ on lower arm switch of half-bridge converter. The voltage across the lower arm switch $V_{\mathrm{AB}}$ can be calculated according to (15) by assigned conduction time $d$ and dc bus voltage $V_{\text {bus }}$. By using resonant tank voltage of (15) and lamp current $i_{r}$ mentioned above, the total load impedance $Z_{\text {total }}$ can be achieved according
TABLE 1: Circuit specification.

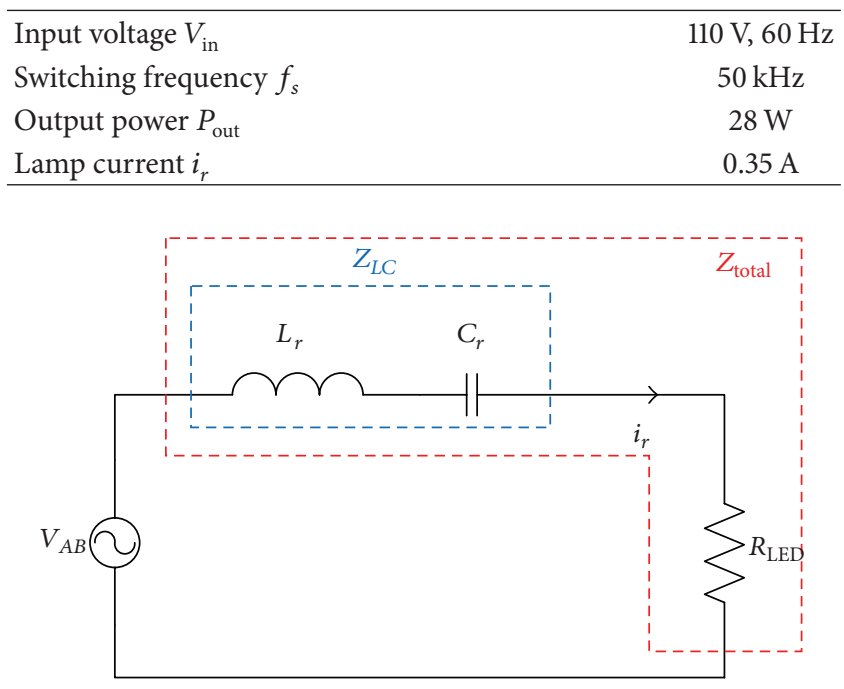

FIGURE 8: Equivalent circuit of resonant tank.

to Ohm's law as illustrated in (16). The relationship between lamp resistance $R$ and reactance of resonant tank $Z_{L C}$ can be expressed as in (17):

$$
\begin{gathered}
V_{\mathrm{AB}}=V_{\text {bus }} \frac{\sqrt{2}}{\pi} \sin (\pi d), \\
Z_{\text {total }}=\frac{V_{\mathrm{AB}}}{i_{r}}, \\
Z_{L C}=\sqrt{Z_{\text {total }}^{2}-R^{2}} .
\end{gathered}
$$

By substituting the assigned switching frequency and resonant tank impedance $Z_{L C}$ determined by (17) into (18) and circuit design resonant frequency into (19), the parameters of resonant inductor $L_{r}$ and resonant capacitor $C_{r}$ will be obtained by solving the simultaneous equations (18) and (19):

$$
\begin{gathered}
Z_{L C}=2 \pi f_{s} L_{r}-\frac{1}{2 \pi f_{s} C_{r}}, \\
f_{r}=\frac{1}{2 \pi \sqrt{L_{r} C_{r}}} .
\end{gathered}
$$

\section{Experimental Results}

This research employs the above-derived circuit parameters to implement a $28 \mathrm{~W}$ LED lighting driving circuit. The corresponding circuit specification is listed in Table 1.

Figure 9 displays the waveforms of input voltage $V_{\text {in }}$, input current $i_{\text {in }}$, and PFC inductor current $i_{L_{\mathrm{PFC}}}$. By inspecting the relationship between input voltage $V_{\text {in }}$ and input current, the small phase angle difference implies that high power factor is predictable. According to the measurement, the power factor is over 0.97 .

Figure 10 demonstrates waveforms of triggering signals $V_{\mathrm{GS} 1}, V_{\mathrm{GS} 2}$, and PFC inductor current $i_{L_{\mathrm{PFC}}}$. It can be seen 


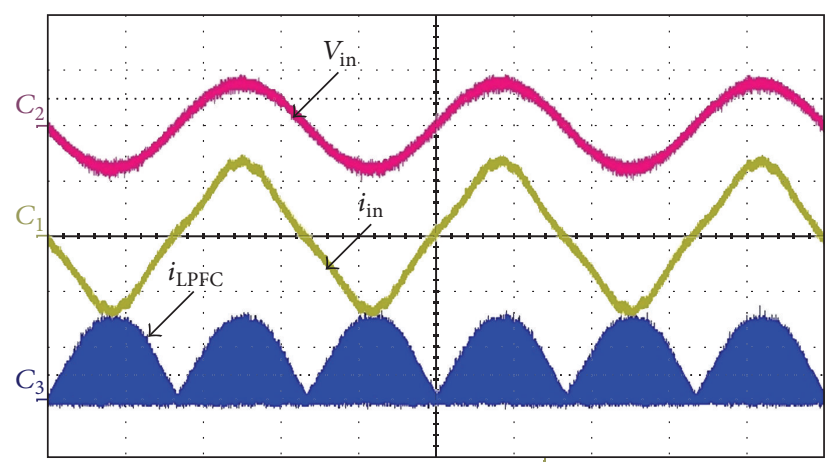

$V_{\text {in }}: 200 \mathrm{~V} /$ div; $i_{\text {in }}, i_{\text {LPFC }}: 2 \mathrm{~A} /$ div; time: $5 \mathrm{~ms} /$ div

FIGURE 9: Input voltage, input current, and PFC inductor current waveform.

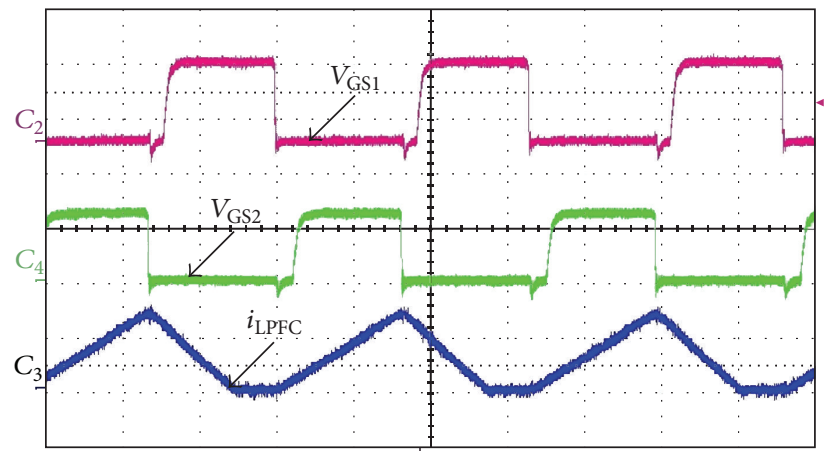

$V_{\mathrm{GS} 1}, V_{\mathrm{GS} 2}: 10 \mathrm{~V} / \mathrm{div} ; i_{\mathrm{LPFC}}: 2 \mathrm{~A} / \mathrm{div}$; time: $5 \mu \mathrm{s} / \mathrm{div}$

FIGURE 10: Switch triggering signal and PFC inductor current waveforms.

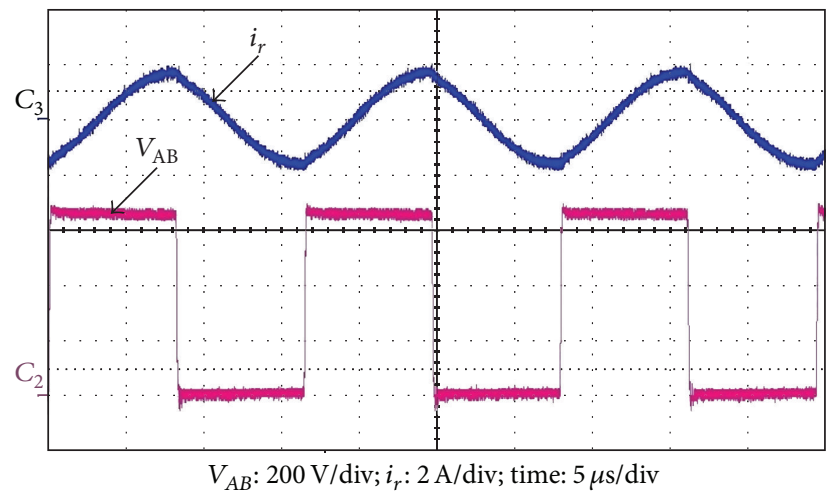

FIGURE 11: Waveforms with square wave voltage leading to resonant current.

that the PFC inductor begins to store energy after turning on switch $V_{\mathrm{GS} 2}$. On the contrary, the PFC inductor releases energy as the switch $V_{\mathrm{GS} 2}$ turns off. The stored energy on PFC inductor ought to be released before next turn-on of $V_{\mathrm{GS} 2}$; therefore, $\mathrm{PFC}$ must be operated with discontinuous conduction mode.

Figure 11 displays the resonant current and voltage waveforms. It can be observed that the resonant voltage $V_{\mathrm{AB}}$ leads resonant current $i_{r}$. The operation is controlled in the

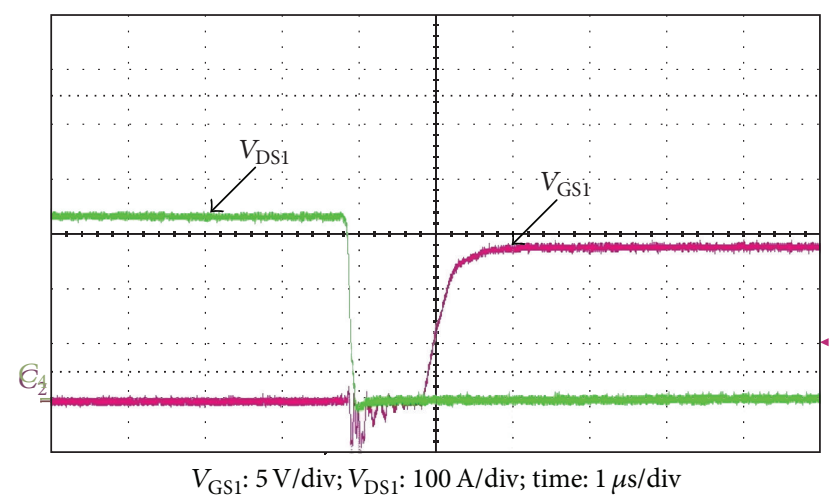

FIGURE 12: Zero-voltage-switching waveform.

inductive mode and furnishes the half-bridge resonant switch with zero-voltage-switching feature. Zero-voltage switching can effectively reduce the high frequency switching loss and, thus, promote the overall circuit operating efficiency.

Figure 12 illustrates that power transistor is triggered by $V_{\mathrm{GS} 1}$ and then turns on, with $V_{\mathrm{DS} 1}$ falling down to zero. If trigger signal $V_{\mathrm{GS} 1}$ is high, the power switch is turned on and $V_{\mathrm{DS} 1}$ falls down to zero. In this way, the simultaneous high states of $V_{\mathrm{GS} 1}$ and $V_{\mathrm{DS}}$ are avoided. The switching actions are always completed when $V_{\mathrm{DS} 1}$ is zero, that is, zero-voltage switching (ZVS).

\section{Conclusion}

This paper realizes a self-excitation single-stage high power factor driving circuit for LED lighting. Experimental results validate the availability of this circuit configuration. The presented self-excitation single-stage high power factor driving circuit can effectively avoid the IC cost, achieve high power factor over 0.97 , and promote power efficiency to over $85 \%$. In consequence, this paper has successfully realized a selfexcitation single-stage high power factor driving circuit for LED lighting.

\section{Conflict of Interests}

The author declares that there is no conflict of interests regarding the publication of this paper.

\section{References}

[1] C. Y. Chen, T. H. Yang, C. H. Hsu, and C. C. Sun, "High-efficiency white LED packaging with reduced phosphor concentration," IEEE Photonics Technology Letters, vol. 25, no. 7, pp. 694-696, 2013.

[2] Z. Chen, Q. Zhang, F. Jiao et al., "Study on the reliability of application-specific LED package by thermal shock testing, failure analysis, and fluid-solid coupling thermo-mechanical simulation," IEEE Transactions on Components, Packaging and Manufacturing Technology, vol. 2, no. 7, pp. 1135-1142, 2012.

[3] Z. Liu, S. Liu, K. Wang, and X. Luo, "Optical analysis of phosphor's location for high-power light-emitting diodes," IEEE 
Transactions on Device and Materials Reliability, vol. 9, no. 1, pp. 65-73, 2009.

[4] C. A. Cheng, H. L. Cheng, C. W. Ku, and T. Y. Chung, "Design and implementation of a single-stage acoustic-resonance-free HID lamp ballast with PFC," IEEE Transactions on Power Electronics, vol. 29, no. 4, pp. 1966-1976, 2014.

[5] H. L. Cheng, C. S. Moo, C. S. Yang, and C. K. Huang, "Analysis and implementation of an HPF electronic ballast for HID lamps with LFSW voltage power conversion conference-nagoya," IEEE Transactions on Power Electronics, vol. 27, no. 11, pp. 4584-4593, 2012.

[6] T. J. Liang, C. M. Huang, and J. F. Chen, "Two-stage high-powerfactor electronic ballast for metal-halide lamps," IEEE Transactions on Power Electronics, vol. 24, no. 12, pp. 2959-2966, 2009.

[7] International electromechanical commission IEC 555-2 standards: Disturbances in supply systems caused by household appliances and similar electrical equipment. Part 2: Harmonics, 1982.

[8] Y. C. Chuang, C. S. Moo, H. W. Chen, and T. F. Lin, "A novel single-stage high-power-factor electronic ballast with boost topology for multiple fluorescent lamps," IEEE Transactions on Industry Applications, vol. 45, no. 1, pp. 323-331, 2009.

[9] C. S. Moo, Y. J. Chen, and W. C. Yang, "An efficient driver for dimmable LED lighting," IEEE Transactions on Power Electronics, vol. 27, no. 11, pp. 4613-4618, 2012.

[10] H. S. Athab, D. D. C. Lu, A. Yazdani, and B. Wu, "An efficient single-switch quasi-active PFC converter with continuous input current and low DC-Bus voltage stress," IEEE Transactions on Industrial Electronics, vol. 61, no. 4, pp. 1735-1749, 2014.

[11] F. L. Tofoli, E. A. A. Coelho, L. C. de Freitas, V. J. Farias, and J. B. Vieira Jr., "Proposal of a soft-switching single-phase three-level rectifier," IEEE Transactions on Industrial Electronics, vol. 55, no. 1, pp. 107-113, 2008.

[12] J. W. Kolar and T. Friedli, "The essence of three-phase PFC rectifier systems. Part I," IEEE Transactions on Power Electronics, vol. 28, no. 1, pp. 176-198, 2013.

[13] H. S. Athab, D. D. C. Lu, and K. Ramar, "A single-switch AC/DC flyback converter using a CCM/DCM quasi-active power factor correction front-end," IEEE Transactions on Industrial Electronics, vol. 59, no. 3, pp. 1517-1526, 2012.

[14] Y. S. Roh, Y. J. Moon, J. C. Gong, and C. Yoo, "Active power factor correction (PFC) circuit with resistor-free zero-current detection," IEEE Transactions on Power Electronics, vol. 26, no. 2, pp. 630-637, 2011.

[15] B. Akin and H. Bodur, "A new single-phase soft-switching power factor correction converter," IEEE Transactions on Power Electronics, vol. 26, no. 2, pp. 436-443, 2011.

[16] T. J. Liang and C. M. Huang, "Interleaving controlled three-leg electronic ballast for dual-HID-lamps," IEEE Transactions on Power Electronics, vol. 23, no. 3, pp. 1401-1409, 2008.

[17] A. E. Aroudi, R. Haroun, A. Cid-Pastor, and L. Martínez-Salamero, "Suppression of line frequency instabilities in PFC ACDC power supplies by feedback notch filtering the pre-regulator output voltage," IEEE Transactions on Circuits and Systems I: Regular Papers, vol. 60, no. 3, pp. 796-809, 2013.

[18] H. L. Cheng, C. A. Cheng, C. C. Fang, and H. C. Yen, "Singleswitch high-power-factor inverter driving piezoelectric ceramic transducer for ultrasonic cleaner," IEEE Transactions on Industrial Electronics, vol. 58, no. 7, pp. 2898-2905, 2011.

[19] S. Y. Chen, Z. R. Li, and C. L. Chen, "Analysis and design of single-stage AC/DC LLC resonant converter," IEEE Transactions on Industrial Electronics, vol. 59, no. 3, pp. 1538-1544, 2012. 

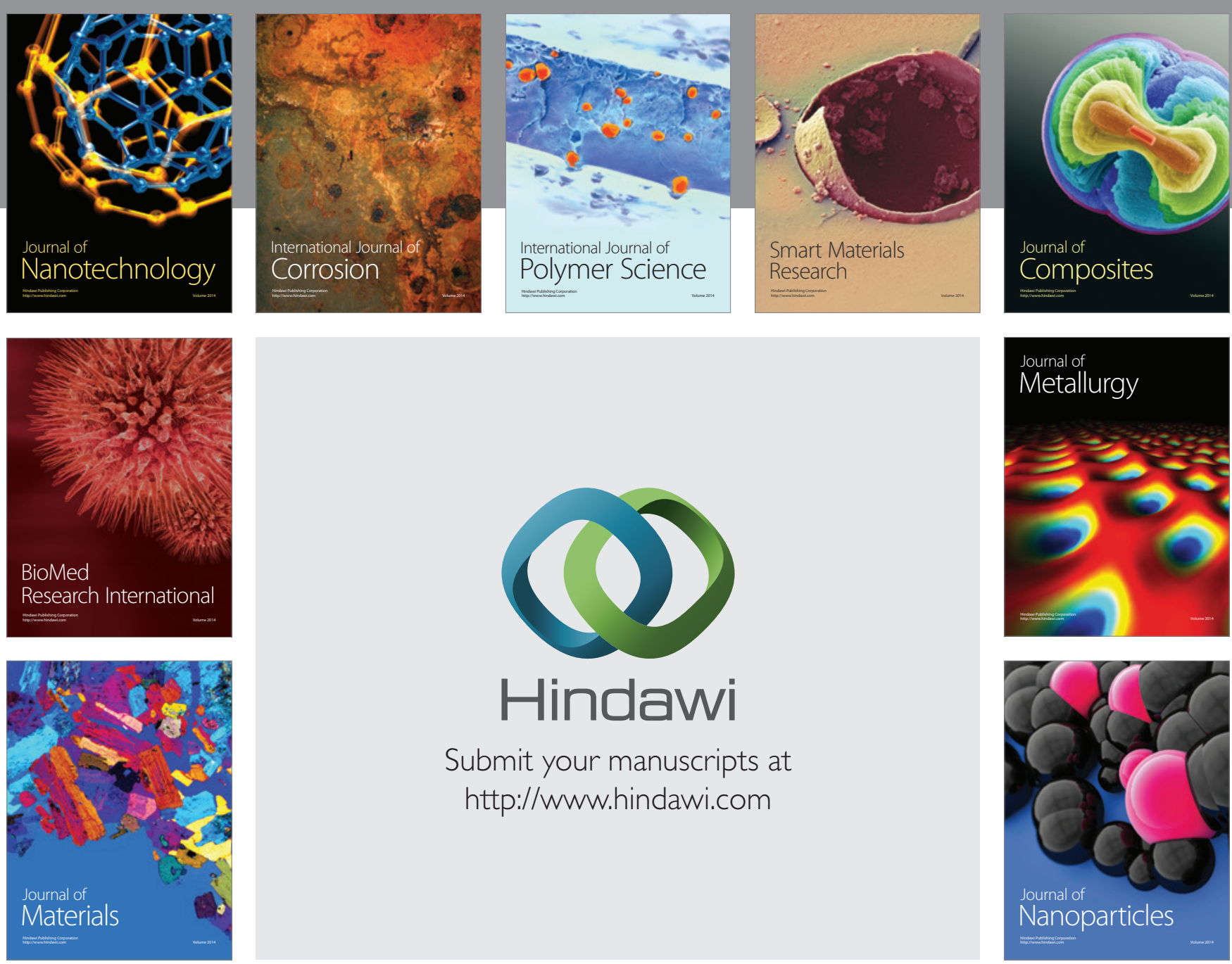

Submit your manuscripts at http://www.hindawi.com
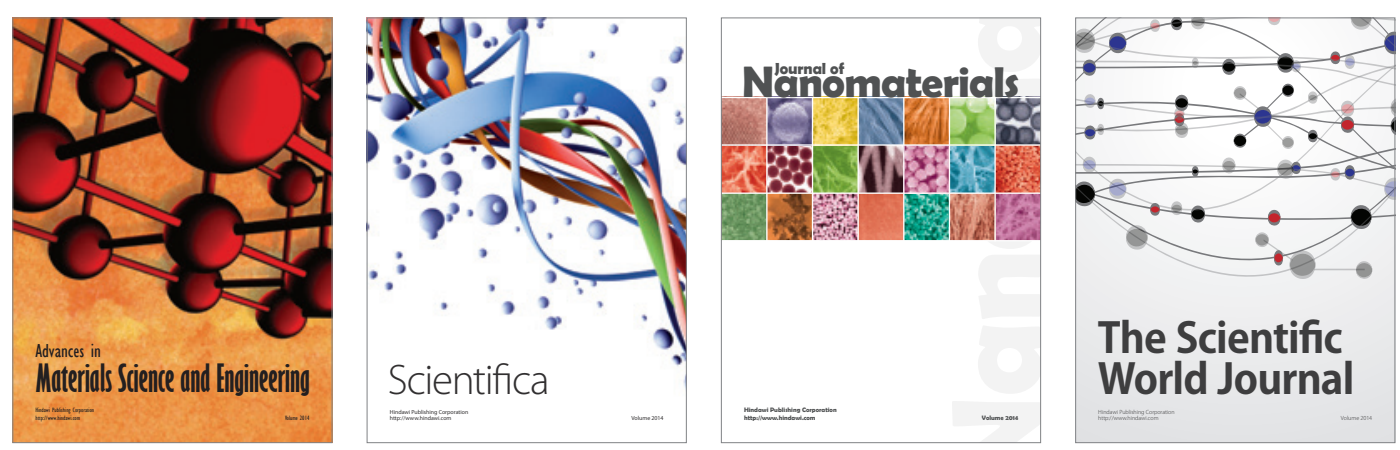

\section{The Scientific World Journal}
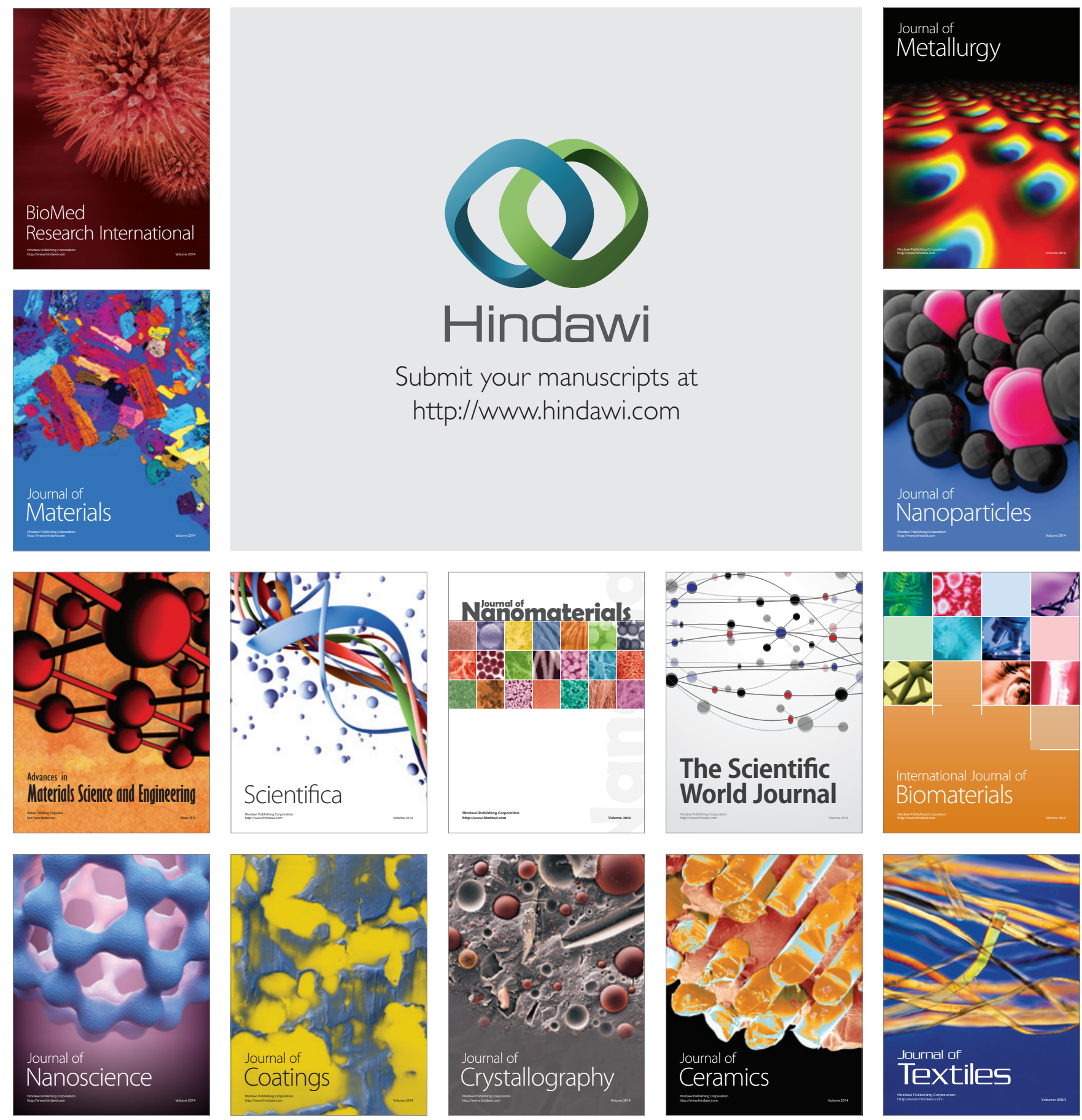